\title{
Implementing Organizational Change through Visioning and Strategic Planning- The CTTransit Experience
}

\author{
Michael A. Sanders \\ Connecticut Department of Transportation \\ David A. Lee \\ CTTransit
}

\begin{abstract}
A visioning and strategic planning process was undertaken at CTTransit beginning in early 1995 that has resulted in fundamental changes in organizational goals and values. A critical aspect of the visioning process was the involvement of union leaders and officials from the Connecticut Department of Transportation (CDOT), as well as the transit system's management, in articulating a shared vision of the future. The new vision has helped to transform the organization from one that was historically reactive and conservative to one that is proactive both in responding to customers and embracing technology. A variety of projects and interdepartmental teams have been organized to carry out five strategic goals for the organization. Parallel changes in CDOT's Bureau of Public Transportation have been implemented.
\end{abstract}

\section{Introduction}

Beginning in early 1995, CTTransit undertook a "visioning" process that has produced a profound transformation of organizational values and a "rethink- 
ing" of goals for the future. Of particular importance has been the involvement of CDOT and local union officials in the visioning process.

Corporate America has long relied upon various tools and techniques to restructure management and help businesses chart their future courses. From management by objectives to strategic planning to total quality management to visioning, all of these processes ultimately serve several basic functions:

- to systematically analyze the conditions affecting an organization;

- to define the organization's mission;

- to articulate the organization's basic values;

- to reach consensus on a desired future;

- to distill the organization's values and future vision into a set of strategic goals;

- to develop an agenda of priority actions to achieve the organization's goals;

- to marshal and allocate the resources necessary to implement action plans; and

- to measure performance toward the accomplishment of the organization's goals and, when necessary, adjust the actions.

There have been numerous noteworthy examples of these processes at work within major U.S. corporations. For instance, several years ago, Sears Corporation diversified its lines of business in order to become the provider of a broad family of consumer services. More recently, Sears announced a new corporate vision that resulted in spinning off subsidiaries such as insurance and real estate companies in order to refocus on its "core business" as a retailer.

The application of strategic management practices to public agencies generally—and to public transit organizations in particular-is not new. Long-standing federal transportation planning requirements have necessitated that local officials envision future service levels and capital needs. Other initiatives, such as Transportation System Management (TSM), planning to comply with Clean Air Act requirements, and "welfare to work" policies, have broadened the mission of transit agencies from merely operating vehicles to serving as instruments of public policy in diverse areas. 


\section{About CTTransit}

CTTransit is the State-owned bus transit system operating in the Hartford, New Haven, and Stamford urbanized areas. CDOT contracts with a private firm, Ryder/ATE, to provide day-to-day management of system operations. The resident management team reports directly to CDOT staff within the Bureau of Public Transportation's Office of Transit and Ridesharing. There is no separate board of directors or other direct oversight of the transit system by city or regional bodies. CTTransit operates a total fleet of approximately 375 buses; employs more than 825 operators, mechanics, and office staff; and administers an annual operating budget of $\$ 54$ million.

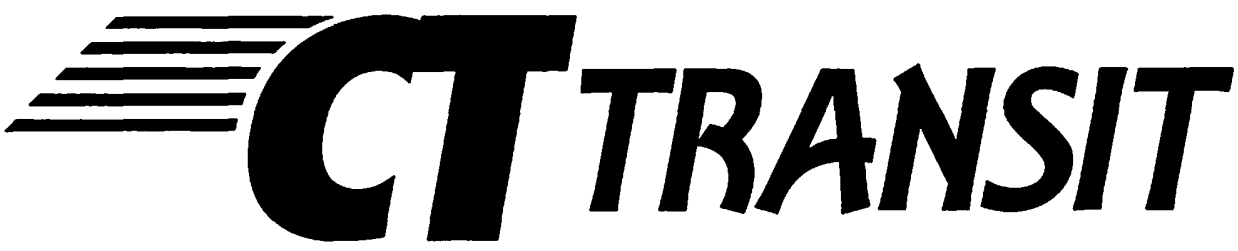

\section{Strategic Planning Among Transit Systems}

Most public transit systems have practiced strategic planning techniques on a more or less formal and/or comprehensive basis. Articulating a mission statement and overall goals and objectives is very useful for building teamwork and developing a sense of common purpose among employees. Strategic planning is often combined with the annual budget process in order to prioritize resource allocations and adopt performance benchmarks. Input to the federally-required, multi-year Transportation Improvement Program likewise provides a framework for future planning on a broader, regional scale.

These processes are usually suitable for organizations whose value systems, missions, and goals are relatively stable and constant over time. This is because conventional corporate planning practices tend to take the existing organizational structure and mission statement as givens. The experience of CTTransit was for management by objectives and annual action planning to reinforce basic company-wide values (e.g., emphasis on adherence to procedures vs. risk-tak- 
ing, antipathy to unproven techniques vs. pioneering new technology, etc.). In addition, by focusing on projects to be completed by existing organizational units (e.g., maintenance, human resources, transportation, etc.), the process reinforced the existing organizational structure. Thus, for example, the action planning process worked best on solving problems within work units; it militated against interdepartmental teaming as a strategy to address company-wide objectives.

\section{Visioning}

Although some have derided visioning as simply the latest in a long line of corporate planning fads, others see the process as an evolutionary step up from traditional strategic management. At its heart, the process seeks to build consensus on a shared "vision" of the future that is unconstrained by existing goals and structures. The vision is described in terms that articulate organizational values and aspirations. Goals and objectives are by-products that flow from the vision, rather than direct products of analyzing problems (the current euphemism is "challenges").

The foundation of visioning is this exercise: "Describe our organization as you would like it to be in the future." One important technique is to express elements of the vision only in positive terms. That is, the process strives for consensus on what the desired future should be, not merely on what present conditions should be changed. In effect, participants are challenged to focus on what the desired future will be like, rather that on what present problems will be solved. For example, a vision statement might include the statement, "Our outstanding service reliability contributes to a high degree of customer satisfaction," rather than "Missed trips due to roadcalls have been reduced."

The latter distinction is subtle, but central, to visioning as a process for transforming organizational values. Conventional management by objectives techniques tend to focus on specific problems and, in doing so, on distinct organizational units-for example, "Roadcalls are a maintenance problem. Reducing roadcalls will be the Maintenance Department's objective this year." Visioning 
challenges the entire organization to recognize that reducing roadcalls is not an end unto itself. Roadcalls can be reduced, but at what cost financially and organizationally? Do other functions suffer in order to meet a goal that in and of itself does not necessarily reflect quality of service or quality of maintenance effort?

Even the objective of improving service reliability is not an end unto itself. Rather, the ultimate goal is to achieve a high degree of customer satisfaction, in part, by operating a highly reliable service. Service reliability becomes an organizational value in which every employee and every department have a stakeand to which most employees and departments can contribute somehow. It is no longer just a "maintenance problem."

Visioning also can help an organization broaden its horizons. Strategic planning techniques that basically build upon an assessment of current organizational strengths and weaknesses are more likely to reinforce the existing organizational mission. By contrast, visioning encourages the organization to at least explore the possibility of broader and more diverse functions. For example, there is a subtle, but critically important, distinction between a transit system whose basic ethos is that of "bus operator" versus a system whose ethos is that of "mobility provider." Likewise, an organization can envision its mission in terms of the public policy goals it serves, rather than just the functions it performs.

\section{Visioning Process at CTTransit}

Prior to 1995, CTTransit used an annual Action Plan process to set priorities and allocate internal resources. The plan included some systemwide projects, such as replacement of fare collection equipment and preparations to host the Special Olympics World Games in New Haven. However, most Action Plan projects were carried out within individual departments and were usually exclusive to that one operating unit. In reality, the Action Plan became a "to do" list for a unit, but not necessarily with the whole company in mind.

The Action Plan lacked the vitality that comes from interdisciplinary thinking and a common vision. The role of CTTransit as "merely a bus operator" was emphasized and was reinforced to some extent by long-standing direction from 
the system's owner, CDOT. But, by early 1995 , several forces had converged that warranted a different approach to strategic planning within CTTransit.

For the first time in several years, there had been changes in the makeup of both the CTTransit management team and key officials in the CDOT Bureau of Public Transportation that motivated a reappraisal of the system's goals and objectives. A fundamental part of the change was an insistence that CTTransit and CDOT management provide proactive leadership for the system, and not merely act as stewards. The new CDOT administrators made clear their expectation that transit management adopt a new direction and a new style of leadership.

Also, for the first time in several years, CTTransit had experienced a significant decline in ridership, especially in the Hartford area. Service levels, rid-

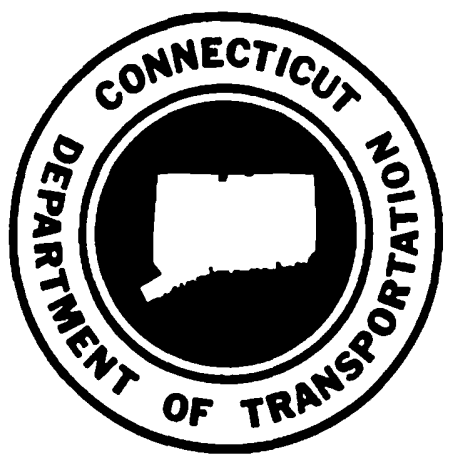

ership, and fares had remained remarkably stable throughout the 1980s. The ridership decline experienced in the early 1990s warranted a redirection of service planning and a new emphasis on marketing and market research techniques in order for the system to survive and maintain a meaningful public service role.

Finally, major capital development programs, which occupied the energies of system management and CDOT officials during the 1980s, were largely complete. By 1995, all of CTTransit's pre-1988 bus fleet had been, or was in the process of being, replaced. The modernization of operating facilities in Hartford and Stamford and the acquisition of major new radio communications, fare collection, and computer systems were also completed. 
CTTransit thus enjoyed a heretofore unavailable opportunity to market attractive bus service to the public and address the external challenges of the changing role of transit in its service areas, while working with supportive leadership, albeit in a severely-constrained fiscal environment. In one sense, CTTransit is unique because the transit system's management team reports directly to CDOT staff, rather than to elected officials or a publicly-appointed policy board. This arrangement certainly facilitated the visioning process, once the CDOT officials involved had recognized a need for change. However, there is no reason why another transit system with a more conventional type of policy board could not similarly pursue a visioning process.

In February 1995, a retreat unprecedented in the history of CTTransit was held that involved all members of the executive management staff, business agents from the three union locals representing CTTransit drivers and mechanics, and key staff from the CDOT Bureau of Public Transportation. A professional outside facilitator was engaged to lead the attendees through a two-day, off-site visioning process. Putting all the players together in the same room was historic. Sharing thoughts, ideas, and desires for the system within this group for two days was often revealing, and sometimes painful.

Involving union leaders from the beginning was essential to help communicate the organizational vision to rank and file employees. While CTTransit had a previous track record of involving union employees on project groups that targeted single issues, this was the first time that union leaders had been involved in real policy planning. The union leaders who attended the retreat readily appreciated that a continuing ridership decline negatively affects all employees. Thus, they were strongly supportive of a vision they felt could only mean more work - and more prosperous working conditions-for their members.

If anything, the "painful" aspect of engaging in a candid reappraisal of organizational aspirations and values was having to question what some felt were "tried and true" management principles (e.g., "if it ain't broke, don't fix it"). Ultimately, when everyone accepted that the status quo could not endure, that CDOT officials expected change, and that not changing would ultimately prove 
more painful than changing, major progress towards articulating a shared vision of the future began.

That meeting formally began a new era for CTTransit. In many respects, what ensued over the following 20 months was more important than what actually took place during the retreat. However, in the course of having each attendee articulate his or her image of a future CTTransit, and in crafting a new mission statement for the organization, consensus through communication and compromise emerged on a shared vision of the future that broke dramatically with past goals and strategies in several key areas.

Historically, one of the principal marching orders for CTTransit management was to "serve demand." In effect, CTTransit would provide service for existing customers, but would not set out to develop new markets or market new services. The new vision embraced the concept of implementing a pro-active and market-driven approach to service planning and marketing, including special emphasis on market research techniques to identify potential customers and communications techniques to enhance the public image of transit.

Similarly, CTTransit was not historically renowned for technological leadership. Some unfortunate experiences with new buses and fare collection equipment in the late 1970s created an atmosphere that did not welcome "cutting edge" technology. In other areas, such as the radio system, CTTransit enjoyed relatively new, but also relatively old-fashioned, equipment. The new vision embraces technological solutions and promotes CTTransit's role as a technical services leader for transit in Connecticut.

The key values that emerged from the visioning process were distilled into the following "Vision Statement" for CTTransit:

\section{We envision CTTransit being one of the premier transpor- tation systems in the United States. There are four key di- mensions of this vision:}


- We are pro-active in effectively developing and marketing services for current and potential customers.

- We are recognized as an industry leader in applying stateof-the-art technology to improve the quality of service and efficiency of operations and administration.

- CTTransit management is recognized for bold, innovative leadership that is highly respected both within and outside the organization.

- We are successful in fulfilling our mission to work together to move people on a high quality system that is safe, reliable, and efficient.

A key element in the visioning process was to update CTTransit's longstanding Mission Statement. The final key dimension above contains several subtle, but very significant, changes. In particular, the former mission statement emphasized "operating service," whereas the new mission emphasizes "moving people." This change reflects a recognition of the role CTTransit can play as an instrument of larger public policy efforts to improve urban mobility and enhance the efficiency of the entire transportation system.

The revised mission statement also emphasizes "working together." This emphasis reflects the participation of labor, management, and government that is central to realizing the vision for the future. It also underscores a commitment to use more interdepartmental mechanisms, rather than to compartmentalize action planning within existing organizational units.

It has been observed that the Vision Statement makes no direct reference to "customer satisfaction." This was not a deliberate omission. Perhaps customer satisfaction was not mentioned because it was already perceived to be a major strength of the transit system. Or, perhaps, satisfaction as a "measured" perception by the customer was not the visionary ideal, but, rather, the vision was to provide a high-quality and customer-focused product. In any event, customer 
satisfaction will continue to be measured and tracked as a performance indicator.

\section{Strategic Goals and Action Plans}

After consensus was reached on the vision and mission statements, the next step was to develop a set of strategic goals. These represent priorities to fulfill the vision, around which specific action plans are developed and prioritized. For CTTransit, five specific strategic goals were identified. In order to communicate the goals effectively to all employees, each was described with a shorthand slogan, as follows:

Attract New Customers. Implement a pro-active and market-driven approach to service planning and marketing.

Get Our Message Across. Promote a positive public image with improved, user-friendly communications.

Be a Technical Services Leader. Establish CTTransit as an industry leader in such areas as maintenance skill training and development of an in-house research and testing capability.

Embrace New Technology. Develop and implement a long-range capital plan emphasizing opportunities for technological innovation to improve the efficiency of operations and administration.

Stress Safety. Increase safety and security of people and property.

A brainstorming approach was used to identify lists of possible projects or action plans that could contribute to achieving each strategic goal. For example, possible projects to enhance the public image of CTTransit included improved complaint-handling procedures, increased coordination of transit and ridesharing promotions, improved signage and passenger amenities at bus stops, and a new, bolder corporate logo and paint scheme. Possible projects to establish CTTransit as a technical services leader include developing a Connecticut Transit Technical Institute within the Maintenance Services Department, promoting technical training for both CTTransit employees and other systems, and encouraging partnerships with Connecticut industry, universities, and other agencies to demonstrate new technologies. 
The next step was to appoint cross-organizational teams to further refine and prioritize projects for each strategic goal and to identify preliminary budgets, funding sources, implementation schedules, and performance milestones. Within CTTransit it was especially important to ensure that these teams provide opportunities for staff from different departments to participate in a joint effort along with $\mathrm{CDOT}$ and union representatives. Bargaining unit employees are paid for their time serving on committees.

The technology-oriented goals mainly lent themselves to specific projects, while planning and marketing goals lent themselves to ongoing working groups. The safety-related goal lent itself to a combination of both approaches.

\section{Implementing Technology Goals}

Specific projects to implement the goals of "Become a Technical Services Leader" and "Embrace New Technology" include the following:

- Emissions Testing of EPA Approved Engine Rebuild TechnologiesCTTransit became the first transit system in the country to install and test Englehard and Johnson-Matthey catalytic mufflers for heavy duty urban transit buses.

- Upgrading of Chassis Dynamometer to Simulate Actual Driving Conditions-This project is currently under way for completion scheduled in 1997.

- Demonstration of Small Specialty Coaches-This project is also currently under way, awaiting final approval of FTA funding.

- Expansion of Maintenance Training Programs - CTTransit has received national recognition for in-house training on basic $\mathrm{AC}$ electricity, braking systems, and steering. During 1996, in-house training programs were offered at cost to employees of other State-funded transit operations.

- Implementation of a Maintenance Apprenticeship Training ProgramThis provision was successfully negotiated as part of a new union contract agreement in 1996.

- Implementation of Cooperative Research Projects with Connecticut Industries and Education Institutions - CTTransit has worked closely with 
International Fuel Cells in their federally-funded project to develop a prototype fuel cell powered bus. CTTransit also has continued to work closely with the University of Connecticut's Transportation Institute to implement a curriculum of training for transit managers.

- Implementation of Technology Application Projects through the Capital Budget - Ongoing projects include upgrading the computer networks in all divisions, automating dispatch and timekeeping functions, expanding the laserdisc digital photolog of bus routes, upgrading scheduling and customer services computer systems, implementing a fully automated fluids management system, and implementing a Maintenancé Reference Display System (replacing repair manuals with information available on CD-ROM).

Other projects to be implemented in 1997 and future years include establishing a CTTransit Technical Institute, investigating the feasibility of AVL technology, developing the capability for on-line passenger information, and expanding applications for bar coding technology in the maintenance area.

\section{Implementing Planning and Marketing Goals}

Five teams have been established to coordinate a wide variety of activities to achieve the Strategic Goals for planning and marketing. It has been especially important in organizing the teams that members are drawn from different levels and units of the organization, from CDOT staff, and even from outside the organization (for example, the general manager of a major suburban shopping mall has been an active member of the Service Design and Development team). All participants attended a special day-long training on the teaming process. The teams' accomplishments to date are summarized below.

\section{Business Development}

This team focuses on how to increase ridership by working cooperatively with employers and retailers. The team's efforts were instrumental in establishing a full-time Business Development function within the CTTransit staff and planning a series of co-promotions around the theme "Our customers are your customers and employees." 


\section{Customer Service}

This team's first project is focused on designing a more customer-friendly timetable format.

\section{Service Design and Development}

This team's first project resulted in the recent implementation of CTTransit's first new local bus route in more than 15 years to provide improved suburb-tosuburb service and more convenient transfer connections to the Hartford area's fastest growing retail and employment hub.

\section{Bus Stop Amenities}

This team focuses on how to respond more effectively to customers' desire for weather protection, security, and information at bus stops and to appreciate bus stops as "portals" to the transit system. As a result of this team's efforts, a proposal to implement a regional passenger waiting shelter program financed with advertising revenue is being developed for presentation to the Council of Governments' Transportation Committee in the Hartford area.

\section{Express Service}

This team's first project has developed a recommendation to extend the "guaranteed ride home" program to monthly bus pass riders on CTTransit's premium-fare express services.

In the future, other possible issues to be addressed with the teaming process could include fare simplification, transfers with other carriers, paratransit, and outreach to community groups.

\section{Implementing Safety Goals}

For the "Stress Safety" goal, a combination of current projects, new projects, and ongoing working groups have been implemented.

Current projects include a demonstration of bus on-board video equipment, the "Safety Sweepstakes" program for operators, a campaign to reduce the incidence of multiple-claim accidents, and participation in a study to reduce injuries by designing a new bus operator's workstation using ergonomic principles. 
New projects include developing a program similar to "Safety Sweepstakes" for maintenance employees, developing a computerized accident data base, implementing campaigns to reduce passenger injuries due to snow and ice on bus steps, and developing a preventable injury policy for employees.

Employee Safety and Health Committees have been established in all divisions to serve as ongoing working groups to deal with such issues as promoting safety awareness, reducing vandalism and assault incidents, improving safety when boarding/alighting passengers who use wheelchairs, and enhancing office ergonomics.

\section{Parallel Organizational Changes at CDOT}

The visioning process created the atmosphere that fostered the new interdisciplinary and team-oriented organizational structure at CTTransit. However, it also influenced a change at CDOT. In November 1995, the structure of the Office of Transit and Ridesharing was simplified to centralize all transit administrative and planning activities into one unit, and all capital project development activities into another.

Simultaneously, several working groups were created in the areas of service development, marketing, and capital projects. These groups comprise members of the Transit Office, Rail Office, Fiscal Office, Policy and Planning Bureau, CTTransit, and representatives from the regional ridesharing brokerages. The interrelationships between the CDOT working groups and the CTTransit teams enhance the effectiveness of the work efforts by CTTransit, as well as providing consistency of programs and products for other State-owned, non-CTTransit transit systems.

\section{Continuing the Process}

Over the next two to three years, these various projects, teams, and working groups will form the basis for organizing the joint efforts of CTTransit management, CDOT staff, and union leaders to achieve the Strategic Goals articulated through the visioning process. Employees at all levels throughout the organization will be actively involved and progress will be monitored regularly so that 
the successful completion of each task can be appreciated as a step toward realizing a vision of the future for the entire company. And we must continue to recognize that reaching the vision is not only a means of organizing our resources, but a process of expressing our aspirations. If we conduct ourselves every day in a way that helps us address the vision, then we have truly reinvented our philosophy and our management and work processes.

\section{References}

Farkas, Z. A., and M. Ayele. 1988. A Guide to Strategic Planning for Transit Properties, Final Report. Project MD-11-0007, prepared for the Urban Mass Transportation Administration by the Center for Transportation Studies, Morgan State University, December 31 .

Hemily, B. 1986. Strategic Planning in Small and Medium-Size Transit Agencies, A Discussion of Practice and Issues, Final Report. Document No. DOT-I-87-15, prepared for the Urban Mass Transportation Administration by the Institute for Urban Transportation, Indiana University, August.

Huffmire, D. W. 1995. Handbook on Strategic Management for Transit Managers. Prepared for the Region I University Transportation Center by the School of Business Administration, University of Connecticut, March.

Lee, D. A., and M. A. Sanders. 1996. Implementing a Visioning and Strategic Planning Process at CTTransit. Transportation Research Record No. 1521, Washington, D.C.: National Academy Press.

MacDorman, L. 1995. The Quality Journey: A Roadmap for Public Transportation. Final Report, Project F-3, Transit Cooperative Research Program, Washington, D.C.: Transportation Research Board, July.

Spraul, W. R. 1995. A Revolution at Metro: Winning the War Against Bureaucracy. Paper presented at the 1995 American Public Transit Association Bus Operations and Technology Conference, May. 


\section{About the Authors}

Michael A. SANDERs has served as Transit and Ridesharing Administrator for the Connecticut Department of Transportation since 1994. His responsibilities include policy and administrative oversight of State programs in urban and rural transit, Americans with Disabilities Act paratransit, ridesharing and transportation demand management, as well as motor transport regulatory and administrative law programs. He holds bachelor's and master's degrees in Geography from Binghamton University and a Master's in Business Administration from Pace University in White Plains, New York $\mathrm{He}$ is a member of the Board of Directors of the American Public Transit Association, Region I, which encompasses the New England states and New York.

DAvid A. LeE is an associate of Ryder/ATE Management and Service Company and currently serves as General Manager of CTTransit. He joined the management team at CTTransit in 1983 as Assistant General Manager for Administration and was AGM for Transit Operations from 1991 to 1995 . He holds a bachelor's degree from Colgate University and a master's degree in political science from the George Washington University and is the Immediate Past President of the New England Passenger Transportation Association. 